\title{
Exponential growth combined with exponential decline explains lifetime performance evolution in individual and human species
}

\author{
Geoffroy Berthelot • Stéphane Len • Philippe Hellard • Muriel Tafflet • \\ Marion Guillaume • Jean-Claude Vollmer • Bruno Gager • Laurent Quinquis • \\ Andy Marc • Jean-François Toussaint
}

Received: 25 February 2011 / Accepted: 23 May 2011 / Published online: 22 June 2011

(C) The Author(s) 2011. This article is published with open access at Springerlink.com

\begin{abstract}
The physiological parameters characterizing human capacities (the ability to move, reproduce or perform tasks) evolve with ageing: performance is limited at birth, increases to a maximum and then decreases back to zero at the day of death. Physical and intellectual skills follow such a pattern. Here, we investigate the development of sport and chess performances during the lifetime at two different
\end{abstract}

G. Berthelot and S. Len contributed equally to the study.

Electronic supplementary material The online version of this article (doi:10.1007/s11357-011-9274-9) contains supplementary material, which is available to authorised users.

G. Berthelot $\cdot$ S. Len $\cdot$ P. Hellard $\cdot$ M. Tafflet $\cdot$

M. Guillaume · J.-C. Vollmer · B. Gager $\cdot$ L. Quinquis •

A. Marc $\cdot$ J.-F. Toussaint

IRMES, INSEP,

11 avenue du Tremblay,

75012 Paris, France

G. Berthelot $(\bowtie) \cdot$ J.-F. Toussaint

Faculty of Sciences, Paris Descartes University,

Paris, France

e-mail: geoffroy.berthelot@insep.fr

M. Tafflet

INSERM,

U970, 56 rue Leblanc,

75015 Paris, France

J.-F. Toussaint

Centre d'Investigation en Médecine du Sport (CIMS),

Hôtel-Dieu, Assistance Publique-Hôpitaux de Paris,

Paris, France scales: the individual athletes' careers and the world record by age class in 25 Olympic sports events and in grandmaster chess players. For all data sets, a biphasic development of growth and decline is described by a simple model that accounts for $91.7 \%$ of the variance at the individual level and $98.5 \%$ of the variance at the species one. The age of performance peak is computed at 26.1 years old for the events studied (26.0 years old for track and field, 21.0 years old for swimming and 31.4 years old for chess). The two processes (growth and decline) are exponential and start at age zero. Both were previously demonstrated to happen in other human and non-human biological functions that evolve with age. They occur at the individual and species levels with a similar pattern, suggesting a scale invariance property.

Keywords Ageing - Maximum performance · Biphasic development. Sport

Sport performances analysis revealed a large progression rate after 1896 (Berthelot et al. 2008, 2010a, b; Desgorces et al. 2008). These enhancements coincided with major improvements in other human activities: energy production, water supply, transports, knowledge and science. Agriculture yields also dramatically evolved during the same period and enabled a sustainable growth of population. Initially triggered by the industrial revolution, this resulted in a great increase of life expectancy (Fogel 2004). Such a process may be referred to as a large phenotypic 
expansion, as mankind optimized its performance potential over less than ten generations.

Despite the strong development of sports performances over the last century, the asymptotic progression pattern demonstrated in several disciplines (Berthelot et al. 2008, 2010a, b; Desgorces et al. 2008) suggests that our progression as a species may soon reach its limits. Nowadays, major efforts are aimed at optimizing the processes that may further improve performance in all human domains. Among them, the process of selecting and hiring future elite performers is partly based on the assessment of individual performances at a young age (Hoye et al. 2009). The selected athletes are expected to progress and reach a peak under appropriate training programmes. Performance is thus used to determine their ability to later compete with and surpass others.

Age is also the main determinant in the decline of physical and intellectual capacities. The effect of age has been assessed at the cellular level (Kitani 2007), in several physiological functions (Kühnert and Nieschlag 2004; Aguilaniu et al. 2008; Fotenos et al. 2008; van Disseldorp et al. 2008) and can also be observed in various forms of human performance, such as sports (Baker et al. 2003; Balmer et al. 2008; Fair 2007; Tanaka and Seals 2003, 2008; Wright and Perricelli 2008; Baker and Tang 2010; Young et al. 2008a, b) and chess (Charness and Bosman 1990; Fair 2007), which, respectively, illustrate physical and intellectual capabilities with advancing age. Based on a simple inverted U-shaped function, Moore has studied the effect of age on running speed (Moore 1975).

The present study is based on a large sample of individual data from elite athletes in two major Olympic disciplines (track and field and swimming) and grandmaster chess players. Our aim is to assess and model the physiological development of performances during growth and ageing and demonstrate how simple mathematics can shed light on the result of complex natural processes.

\section{Material and methods}

Data

Two types of data were collected: the individual careers of athletes and the top performances or world records established by age class $\left(\mathrm{WR}_{\mathrm{a}}\right)$. The study of these progressions allows for the measurement of the age of peak performance in both sport and chess. We focus on the non-linear function describing these progressions. In the two studied sports, we covered the full range of Olympic distances; 13 events were chosen in track and field: the $100 \mathrm{~m}$ (men $\mathrm{M}$ and women $\mathrm{W}$ ), $400 \mathrm{~m}$ (M, W), $800 \mathrm{~m}(\mathrm{M}, \mathrm{W}), 1,500 \mathrm{~m}(\mathrm{M}, \mathrm{W}), 5,000 \mathrm{~m}$ (M), 10,000 m (M, W) and marathon (M, W). Data from throwing and hurdle events were not gathered since the rules depend on age. Twelve events were chosen in long course pool freestyle swimming: $50 \mathrm{~m}$ (M, W), $100 \mathrm{~m}(\mathrm{M}, \mathrm{W}), 200 \mathrm{~m}(\mathrm{M}, \mathrm{W}), 400 \mathrm{~m}(\mathrm{M}$, W), $800 \mathrm{~m}(\mathrm{M}, \mathrm{W})$ and 1,500 m (M, W). Datapoints of the best 96 all-time chess grandmasters were gathered.

Individual sport careers

The full career data set corresponds to all performances established by a single athlete and their date of achievement. All are recorded in recognized data sources (IAAF, http://www.iaaf.org; FINA, http://www.fina.org). We selected athletes who established at least one performance in the yearly 10 best ranking in the period from 1980 to 2009. Full archived careers were gathered for 1392 subjects in track and field and 815 individuals in swimming. The date of birth of each athlete was recorded (IAAF, http://www.iaaf.org; T\&F, http://www. allime-athletics.com). For each year of an athlete's career, when several performances were established, only the best one was kept. The average number of performance points per career was $6.20 \pm 1.36$ in track and field and $6.57 \pm 0.44$ in swimming. These values represent the average number of marks established by the athletes listed in the official databases. The careers containing six or more points well describe the development of performances, so we decided not to restrict the study to the minimum of four points required for each fit. Thus, all careers containing at least six performance points were used for the modelling. We thereafter use the term 'career' to designate the selected performances during the full career of a single athlete.

Individual chess careers

The full career data of chess players were gathered on Jeff Jonas' Chessmetrics (http://db.chessmetrics. com; Howard 2005). This web site lists ranking of top players back into the nineteenth century. We selected the first 96 chess players that show the greatest average ratings and recovered their whole 
career. A total of 34,481 ratings were recovered, and the yearly best performances were selected for each player. The year of birth of each chess player was also recorded.

World records

In addition to the previously gathered data, the best performances of the cadet series (15-16 years old), junior series (17-18 years old) and master series ( $>35$ years old) were also collected for the two sports disciplines (Swimnews, http://www.swimnews.com; Swimrankings, http://www.swimrankings.net; WMA, http://www.world-masters-athletics.org).

The complete data (junior+elite+master series in the two sports and all the whole careers of the chess players) is used to quantify the best performance established for each available age. We thereafter use the term 'age-related world records' or $\mathrm{WR}_{\mathrm{a}}$ to designate this data set.

The model

For chronometric sports events, times (seconds) were converted into speeds (metre per second). Each sport performance is bound to the corresponding age according to:

$t=\Delta Y+\frac{\Delta M}{12}+\frac{\Delta D}{365.25}$

where $t$ (in years) is the age, when a given performance is established; $\Delta Y$ (years) is the difference between the year when the performance is established and the performer birth year; $\Delta M$ (months) is the difference between the performer birth month and the month of performance and $\Delta D$ (days) is the difference between the day of birth and the day of performance. Only the year of birth was available for the chess players.

The model is adjusted to the progression patterns of 1 . all the careers of athletes and chess players and 2. the $\mathrm{WR}_{a}$ for all sports events and chess player using the equation (Moore 1975):

$P(t)=a \times\left(1-e^{b t}\right)+c \times\left(1-e^{d t}\right)$

The coefficients $a, b, c$ and $d$ are estimated using a least-square non-linear regression method with:

$\left\{\begin{array}{l}a, c, d>0 \\ b<0\end{array}\right.$
For an estimated performance $P$, the model can be described as the sum of two von Bertalanffy's growth functions (VBGF): $P(\mathrm{t})=A(t)+B(t)$, where $A(t)$ is the increasing exponential process (first VBGF) and $B$ $(t)$ the decreasing exponential process (the second VBGF is modified with $d>0$ ). The two processes are antagonists, and for appropriate sets of parameters (3), the resulting curve is always hump-shaped: rising at the beginning, reaching a maximum and falling back to zero: the decreasing $B(t)$ process overwhelm the increasing $A(t)$ process. For each event, the exact peak is computed and corresponds to the age when the performance is maximal. The roots of Eq. 2 are also computed for each series.

\section{Results}

A total of 646 careers $(5,167$ performances) were kept for running in track and field, 512 careers $(3,129$ performances) for swimming and 96 careers $(2,969$ performances) for chess players (Online Resource 1). The mean number of careers selected per event is $52.73 \pm 16.26$ (s.d.) for track and field and $42.67 \pm 6.71$ for swimming. All the careers of chess players were kept, as they all included more than six performances. The mean number of performances by career is $6.20 \pm$ 1.36 for track and field, $6.57 \pm 0.44$ for swimming and $31.16 \pm 14.24$ for chess players.

The model describes the development of careers with age in sports and chess (Online Resource 2). The mean adjusted $R^{2}$ for the careers is $0.997 \pm 1.82 \times 10^{-3}$ for track and field, $0.998 \pm 2.29 \times 10^{-3}$ for swimming and $0.755 \pm 1.99 \times 10^{-1}$ for chess. It also describes the development of world records with age in the two disciplines: the mean adjusted $R^{2}$ for the world records is $0.991 \pm 4.05 \times 10^{-3}$ for track and field, $0.987 \pm 6.06 \times 10^{-3}$ for swimming and 0.978 for chess.

In running, the performance peaks at $25.99 \pm 2.13$ on average and the gathered peaks in all events range from 23.29 years old $(10,000 \mathrm{~m} \mathrm{M})$ to 31.61 years old (Marathon M). The mean age of peak performance for swimming is younger than the one of track and field $(20.99 \pm 1.55)$ and ranges from $18.36(1,500 \mathrm{~m} \mathrm{M})$ to $23.14(50 \mathrm{~m} \mathrm{M})$. The mean age of peak performance is 31.39 years for chess.

The average roots value of Eq. 2 of the track and field events is $109.48 \pm 5.97$ years old. Roots range from 98.72 years old $(1,500 \mathrm{~m} \mathrm{~W})$ to $118.91(100 \mathrm{~m} \mathrm{~W})$. 
The average roots value for swimming events is $110.38 \pm 3.23(110.44 \pm 2.14$ for men and $110.31 \pm 4.28$ for women). Roots range from $104.14(50 \mathrm{~m} \mathrm{~W})$ to $115.77(800 \mathrm{~m} \mathrm{~W})$.

The root for chess is 130.14 years old.

\section{Discussion}

The analysis of the age-performance relationship for each of these events suggests a biphasic development with two antagonistic processes. This pattern was first described by Moore using a bi-exponential function (2) on five sports events (Moore 1975). More recently, the declining process was reanalyzed by Donato et al. (2003) and Tanaka and Seals (2008)) and described by Baker et al. (2003), Baker and Tang (2010) and Bernard et al. (2010) using an exponential equation:

$$
Y=1-\frac{\exp ^{\left(T-T_{0}\right)}}{\tau}
$$

Stones and Kozma (1984) and Bongard et al. (2007) also observed and modelled the declining process in a non-elite population and observed a quadratic decrease of performances. A later model investigated the master athletic world records using third order polynomial functions (Rittweger et al. 2009). However, it remained impractical to model the development of performance during the whole lifetime, which could also tend toward positive infinity, making the estimation of life duration unrealistic.

Chess ratings were also shown to follow an increasing and decreasing pattern with age (Charness and Bosman 1990; Roring and Charness 2007) that was not characterized. The model presented by Moore was used here to describe the development of 1 . individual athletes' and chess players' careers and 2 . the world records by age class in swimming and running Olympic disciplines and in chess ratings.

Development of careers and world records with ageing

More than 11,200 performances were used to describe the development of sports and chess careers. While the data used to construct individual careers might remain incomplete (data are not usually recorded at very young ages; many former athletes are still alive, which prevents to record data from their late life), the age span gathered covers a large part of the present human life-span. The model used properly describes the biphasic development of each career (mean $R^{2}=$ 0.92, Fig. 1).

This evolution is also observed for the $\mathrm{WR}_{\mathrm{a}}$ and successfully described by the same model (mean $R^{2}=$ 0.99, Fig. 2a) in both chess and sport (Fig. 2a, b). Using the $\mathrm{WR}_{\mathrm{a}}$ series, we computed the roots of Eq. 2 for each event (Online Resource 2). These correspond to a rough estimate of the maximum life-span. The maximal speed measured in track and field $(100 \mathrm{~m})$ is associated with a value of maximal life-span close to the archived records for both men's and women's longevity (Young et al. 2009). Through the analysis of their human maxima, this holistic model establishes a very coherent link between two major parameters of the phenotype: motion speed and life duration.

The causes and parameters influencing the decline of performances in the process of ageing were and still are extensively investigated (Hayflick 2007; Kitani 2007; Njajou et al. 2010). Donato et al. (2003) previously analysed the performances of American swimmers in US competitions and stated that the magnitude of age-related decline in swimming was smaller than that observed in running. He suggested that it was not due to differences in the training volume with age but rather to a greater reliance on biomechanical technique in swimming. The magnitude of age-related decline in sprint and endurance performances remains a controversial question (Rittweger et al. 2009). Previous studies reported that endurance performance was more affected by age than sprint performance (Baker et al. 2003; Donato et al. 2003). Finally, Wright and Perricelli (2008) and Donato et al. (2003) observed a difference between men and women in track and field and swimming, respectively, and suggested that both the rate and magnitude of decline were greater for women. Fair (2007) investigated and compared the rates of decline in athletics and swimming events as well as chess. In athletics and swimming, he found that both men and women generally revealed larger rates of decline at the longer distances, with a larger rate of decline for women, in accordance with Tanaka and Seals (2003). We show here that these processes are in fact similar and independent from the considered sport, gender, milieu (ground or water) or principal anatomic-physiological medium (muscle, cardiovas- 
a

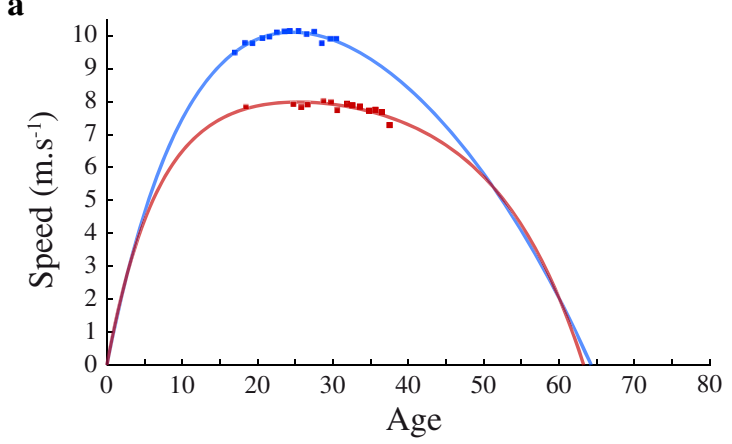

b

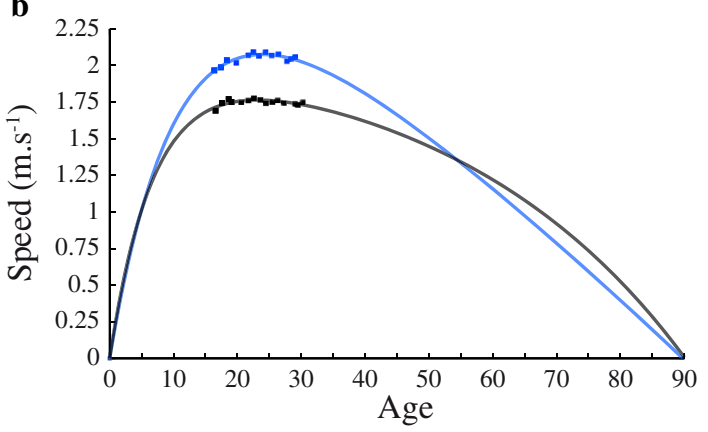

.

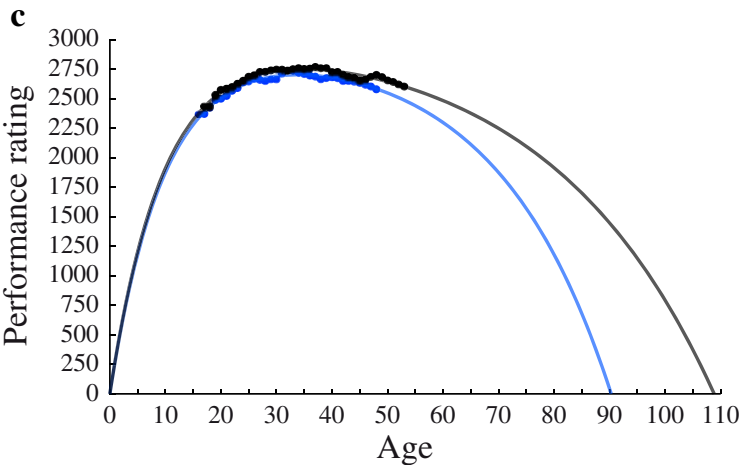

Fig. 1 The model applied at the individual scale (athletes' and chess players' careers). a The model is adjusted to two careers in two track and field events: the $100 \mathrm{~m}$ straight (blue men career: Ato Boldon; adjusted $R^{2}=0.99$ and peak $=24.63$ years old and the $400 \mathrm{~m}$ in track \& field (red women career: Sandie Richards; $R^{2}=$ 0.99 and peak $=25.37)$. b The model is adjusted to two careers in swimming: the $100 \mathrm{~m}$ freestyle (blue men career: Peter van den Hoogenband; $R^{2}=0.99$ and peak=23.92); the $200 \mathrm{~m}$ freestyle (black women career: Martina Morcova; $R^{2}=0.99$ and peak= 23.66). $\mathbf{c}$ The model is adjusted to two careers in chess: Jonathan Simon Speelman (blue): $R^{2}=0.97$ and peak $=33.86$ and Jam Timman (black): $R^{2}=0.95$ and peak $=34.67$

cular system, brain) as they are most strongly related to the effect of time upon all living things: ageing.

The performances were gathered over a 30-year period starting in 1980. Technological, medical and nutritional innovations appeared in this period and influenced the environment around each performance. Recent studies (Berthelot et al. 2008, 2010a; Nevill and Whyte 2005; Nevill et al. 2007) analysed the
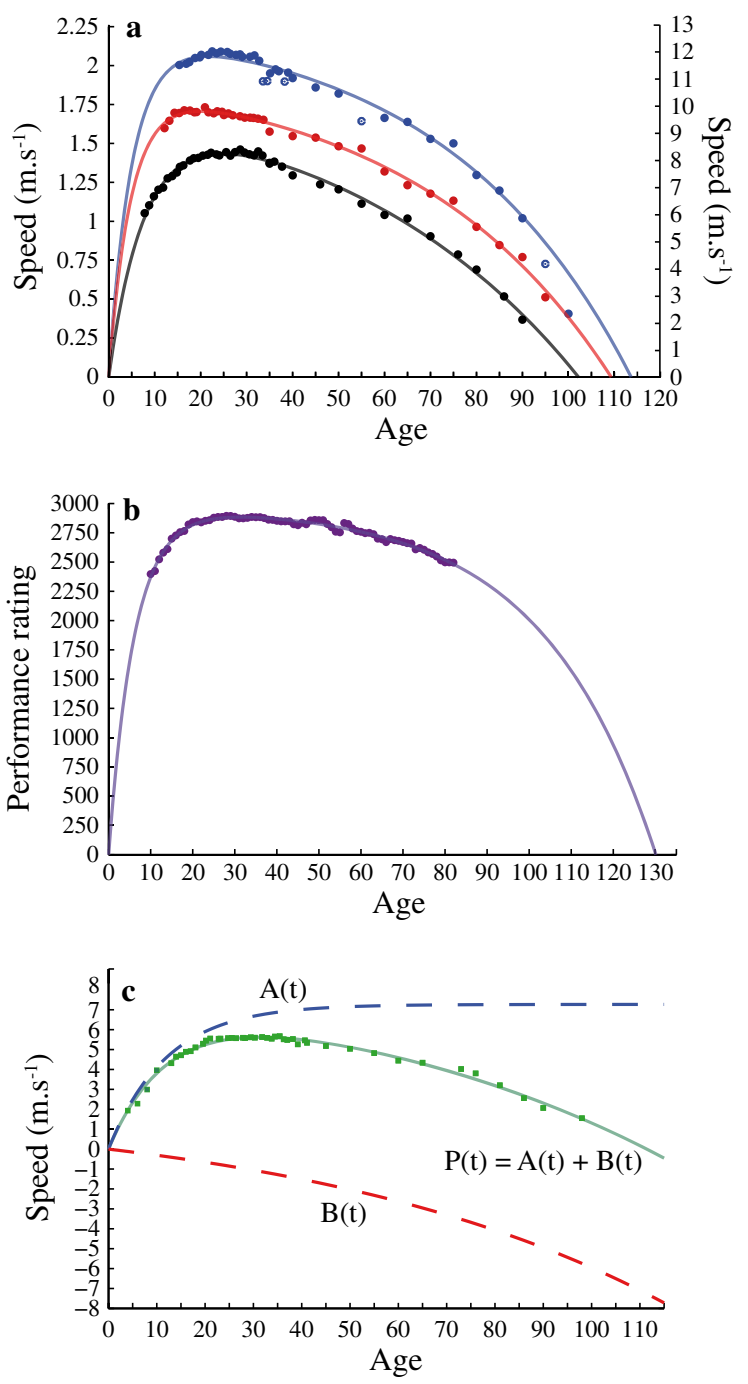

Fig. 2 The model applied at the species scale. For each age, the maximum performance among the studied careers is gathered. a The model is adjusted to two swimming events (left ordinate): $100 \mathrm{~m}$ men (blue, $R^{2}=0.98$ and peak=21.71) and $200 \mathrm{~m}$ women (red, $R^{2}=0.99$ and peak $\left.=20.04\right)$ and to one track and field event (right ordinate): the $400 \mathrm{~m}$ women (black $R^{2}=0.99$ and peak=24.72). $\mathbf{b}$ The model is adjusted to the best chess performance by age: (purple fit) $R^{2}=0.97$ and peak $=$ 31.39. c The marathon event (men) is fitted $\left(R^{2}=0.99\right.$ and peak $=31.61)$. The model used is composed of two antagonists processes: $P(t)=A(t)+B(t)$ (methods) with $A(t)$ the increasing process $\left(A(t)=7.17 \times\left(1-e^{-0.084 \times \text { age }}\right)\right)$ and $B(t)$ the declining process $\left(B(t)=1.84 \times\left(1-e^{-0.014 \times \text { age }}\right)\right)$ 
evolution of world records/top performers and revealed that performances reached a reliable stability during this period. However, all the innovations introduced contributed to widening the sides of the patterns: athletes can compete earlier (at a young age) or later. There is no possibility to precisely quantify the medical or nutritional improvements, which may have introduced a bias in the coefficients assessment or in the measurement of the age of peak performance. In the period and disciplines covered, however, only one major technological innovation was introduced: swimsuits, which induced three bursts in the evolution of performances (Berthelot et al. 2010b). All athletes took advantage of them. This might have led also to a slight overestimation of the age of peak performance in short distance swimming. Other confounding variables may have impacted the performances, but the model shows a very robust adequacy with each series of performances, suggesting that the shape of the pattern is fixed for the studied period.

The progression in performance during the early phase is similar at both careers and $\mathrm{WR}_{\mathrm{a}}$ levels for sport events as well as chess: after the age of performance peak, the decline is described by the same equation. Both careers and age-adjusted world records provide a large coherence to illustrate the impacts of these associated mechanisms. The declining process starts from the origin of each career and each $\mathrm{WR}_{\mathrm{a}}$, i.e. at day zero. It competes against the development process that also starts from the origin, but the former systematically "wins the battle". Performance inevitably returns to zero: for the individual, this represents death. It is inherent to the model and remains inescapable at the individual and at the species level. The opposition between both biological courses may mathematically represent an anabolic and catabolic dialogue, which drives life from the conception of our first cell up to the reproductive acme then down to the last heart beat.

\section{A biphasic development occurring at several scales?}

The model was applied at two different scales: the single career (Fig. 1) and the world records (Fig. 2a). It was also applied in two different disciplines: athletics, swimming and in two different fields: sport and chess. This biphasic development is also observed in other sports, such as tennis, basketball, soccer or baseball, where the age for peak performance appears similar (Schulz and Curnow 1988; Bradbury 2009; Guillaume et al. 2010). It is shared by a large variety of circumstances (Kühnert and Nieschlag 2004; Aguilaniu et al. 2008; Fotenos et al. 2008) suggesting a widespread common process in physiology.

The present analysis demonstrates that this pattern is similar in track and field and swimming, despite the fundamental differences separating the two disciplines. The athletes encounter two fluid mediums, and the magnitudes of the drag forces in air or water are widely different. Running, swimming or flying are techniques developed by organisms to move while minimizing drag and energy losses (Alexander 2005; Bejan and Marden 2006). Such abilities play an important role in the theory of senescence and partly determine the capacity of a predator to catch a prey or the optimal response to danger (Medawar 1952; Williams 1957; Hamilton 1966; Reznick et al. 2004; Carlson et al. 2007). In fact, animal performance (i.e. running, swimming or flying speeds) is critically involved in the escape from predators (Husak 2006; Irschick et al. 2008).

Our results also suggest that this ability to perform may be, to a certain extent, still correlated to life expectancy in the human species. Therefore, the biphasic development described here may also be operant not only in human but in other animal species, such as in insect (Dukas and Visscher 1994) and mammals (Bronikowski et al. 2006). Several studies also demonstrated that the net photosynthesis rate is related to leaf age (Kasemsap et al. 1997; Wullschleger and Oosterhuis 1990) through a biphasic pattern:

$Y=a+b X\left[\exp ^{(c X)}\right]$

The similarity of the mathematical models (2), (4) and (5), used to describe processes that fundamentally differ from one another by their nature or scale, suggests that a common law exists for a sizeable set of biological and physiological phenomena, all undergoing the same decaying process. A large number of biological processes in nature are fractals: they exhibit auto-similar shapes at different scales (Mandelbrot 1982). We show here that the biphasic relation between performance and age exhibits a similar pattern at the individual and at the species level, suggesting a scale-invariant process. The growing 
and declining pattern of performances similarly operates for a living organism (the first studied scale) and a population (the second studied scale). All simultaneous biphasic developments at work determine the life-span of the studied system (cells, organisms, populations, Fig. 3a). This evolution seems to have been optimized through the human phenotypic expansion in the last two centuries (Fig. 3b).

In summary, the development of sport and chess performances during the process of ageing exhibits two coexisting and conflicting processes that result in a biphasic pattern. It is possible to obtain the expected

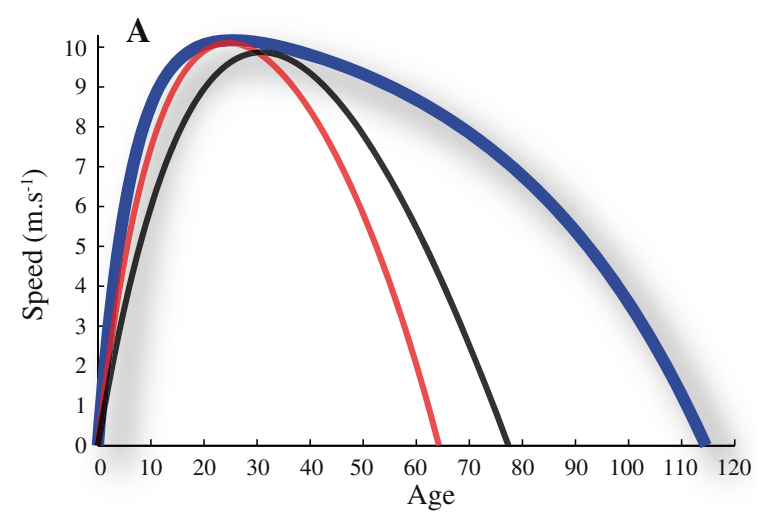

B

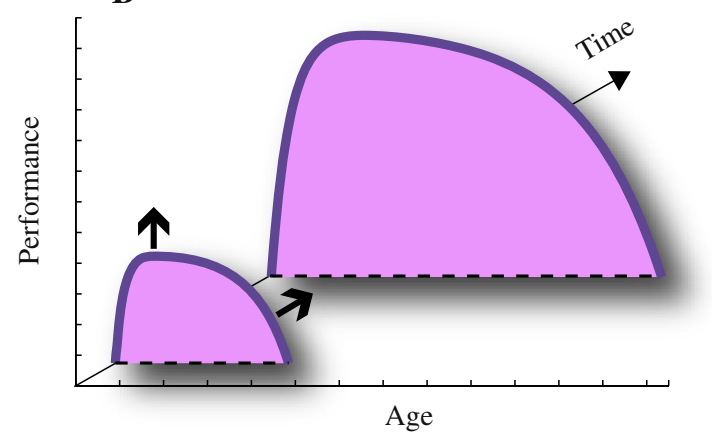

Fig. 3 Scale invariance and phenotypic expansion. a Estimated curves are plotted for two individual careers (red Ato Boldon, $R^{2}=0.99$, peak $=24.63$ at $10.10 \mathrm{~ms}^{-1}$ and roots $=[0,64.27]$ years old; black Johnson Patrick, $R^{2}=0.99$, peak $=30.82$ at $9.87 \mathrm{~ms}^{-1}$ and estimated roots $=[0,77.38]$ years old) and the $\mathrm{WR}_{\mathrm{a}}$ (blue curve) in the $100 \mathrm{~m}$ straight in track and field. The model describes how both individual and species scales are related. b Conceptual framework of the phenotypic expansion at work through the XXth century (z-axis). Both performance (y-axis) and life expectancy ( $x$-axis) were limited in the early times of industrial revolution. Both increased during time (black arrows) and allowed for optimizing the human performance and population life expectancy. The shape of the phenotype was thus extended. It now culminates to an optimum but at the price of high primary energy consumption and by stressing the pressure on the biomass average performance gain from one age to another by deriving the equation on world records. Thus, characterizing the progression and regression of individual athletes or chess players as they age is mathematically feasible and may lead to nomograms with a physiological pattern and to the identification of 'atypical paths' (Berthelot et al. 2010a, b) or abnormal trajectories. The estimated age of peak performance of the world records (26.1 years old) is in accordance with other biological and physiological phenomena such as the age of peak bone mineral density (Boot et al. 2010), the development of the pulmonary function (Schoenberg et al. 1978), the cognitive capacity (Salthouse 2009) or the human reproduction (Kühnert and Nieschlag 2004).

Inherent to these phenomena, the function includes two mathematical terms associated with developmental growth and decline that closely describe performance development and occur at different levels. From a theoretical point of view, it has the selfsimilarity characteristics of a scale-invariant process. Technological improvements and the evolution of rules both led to modifications in the evolution pattern of performances. This may have slightly biased the coefficients assessment and the exact age of peak performance. Further, changes in the environment and increased athlete detection efforts might also have influenced the pattern. However, the model was adjusted with a high adequacy to the series of performances gathered here. It may therefore lead to several applications well outside the field of sport. The investigation of the age of peak performances for different phenomena occurring at different scales might lead to a classification of these phenomena, with early or late peaks. Another implication would be to study the interaction of the two phases at different scales and the development of a method to estimate life expectancy for a set of individuals. Injuries and illness and their impact on performances would also help to estimate their influence on the pattern. The use of QALYs and DALYs could help to model and understand this issue.

The study of the world records progression and top performances revealed a plateau in a majority of studied events. We extended the studied data and the model to a broader context: the development of physiological performance in the process of ageing. This questions the upcoming evolution of the biphasic pattern presented here: will the phenotypic expansion 
continue, plateau or decrease? Do we have the ability to maintain our development in a sustainable way? Current trends and official statements develop multiple scenarios: a better understanding of their different steps and possible regulations will be necessary. Our results might help to define the contours of such questions.

Acknowledgements We thank the INSEP teams, the Fédération Française d'Athlétisme and Fédération Française de Natation for their full support. We also thank the doctoral school Interdisciplinaire Européenne Frontières du Vivant, Programme doctoral Liliane Bettencourt, Universities Paris Descartes and Paris Diderot and are grateful to Bernard Swynghedauw (INSERM), Karine Schaal (IRMES) and Tomasz Wrycza (Max Plank institute) for their helpful review of the article.

Open Access This article is distributed under the terms of the Creative Commons Attribution Noncommercial License which permits any noncommercial use, distribution, and reproduction in any medium, provided the original author(s) and source are credited.

\section{References}

Aguilaniu B, Maitre J, Glénet S, Gegout-Petit A, Guénard H (2008) European reference equations for CO and NO lung transfer. Eur Respir J 31:1091-1097

Alexander RM (2005) Models and the scaling of energy costs for locomotion. J Exp Biol 208:1645-1652

Baker AB, Tang YQ (2010) Aging performance for masters records in athletics, swimming, rowing, cycling triathlon, and weightlifting. Exp Aging Res 36:453-477

Baker AB, Tang YQ, Turner MJ (2003) Percentage decline in masters superathlete track and field performance with aging. Exp Aging Res 29:47-65

Balmer J, Bird S, Davison R (2008) Indoor 16.1-km time-trial performance in 370 cyclists aged $25-63$ years. J Sports Sci 26:57-62

Bejan A, Marden JH (2006) Unifying constructal theory for scale effects in running, swimming and flying. J Exp Biol 209:238-248

Bernard T, Sultana F, Lepers R, Hausswirth C, Brisswalter J (2010) Age-related decline in olympic triathlon performance: effect of locomotion mode. Exp Aging Res 36:64-78

Berthelot G, Thibault V, Tafflet M, Escolano S, El Helou N et al (2008) The citius end: world records progression announces the completion of a brief ultra-physiological quest. PLoS ONE 3(2):e1552. doi:10.1371/journal.pone.0001552

Berthelot G, Tafflet M, El Helou N, Len S, Escolano S et al (2010a) Athlete atypicity on the edge of human achievement: performances stagnate after the last peak, in 1988. PLoS ONE 5(1):e8800. doi:10.1371/journal.pone.0008800

Berthelot G, Len S, Hellard P, Tafflet M, El Helou N et al (2010b) Technology \& swimming: 3 steps beyond physiology. Materials Today 13:56-41

Bongard V, McDermott AY, Dallal GE, Schaefer EJ (2007) Effects of age and gender on physical performance. Age 29:77-85
Boot AM, de Ridder MAJ, van der Sluis IM, van Slobbe I, Krenning EP, de Muinck Keizer-Schrama SMPF (2010) Peak bone mineral density, lean body mass and fractures. Bones 46:336-341

Bradbury JC (2009) Peak athletic performance and ageing: evidence from baseball. J Sports Sci 27:599-610

Bronikowski AM, Morgan TJ, Garland T, Carter PA (2006) The evolution of aging and age-related physical decline in mice selectively bred for high voluntary exercise. Evolution 60:1494-1508

Carlson SM, Hilborn R, Hendry AP, Quinn TP (2007) Predation by bears drives senescence in natural populations of salmon. PLoS ONE 2(12):e1286. doi:10.1371/journal.pone.0001286

Charness N, Bosman EA (1990) Expertise and aging: life in the lab. In: TH Hess (ed) Aging and cognition: knowledge organization and utilization ( $\mathrm{pp}$ 358). Elsevier Science Publishers Chessmetrics. http://db.chessmetrics.com. Accessed 12 February 2010

Desgorces FD, Berthelot G, El Helou N, Thibault V, Guillaume M et al (2008) From Oxford to Hawaii ecophysiological barriers limit human progression in ten sport monuments. PLoS ONE 3(11):e3653. doi:10.1371/journal.pone.0003653

Donato AJ, Tench K, Glueck DH, Seals DR, Eskurza I, Tanaka H (2003) Declines in physiological functional capacity with age: a longitudinal study in peak swimming performance. J Appl Physiol 94:764-769

Dukas R, Visscher PK (1994) Lifetime learning by foraging honey bees. Anim Behav 48:1007-1012

Fair RC (2007) Estimated Age Effects in Athletic Events and Chess. Exp Aging Res 33:37-57

Fogel RW (2004) The escape from hunger and premature death, 1700-2100. Cambridge University Press, Cambridge, New York

Fotenos AF, Mintun MA, Snyder AZ, Morris JC, Buckner RL (2008) Evidence for a relation between socioeconomic status, preclinical Alzheimer disease, and reserve. Arch Neurol 65:113-120

Guillaume M, Len S, Quinquis L, Nassif H, Marc A et al (2010) Age performance relation in Tennis: analysis of top 10 ATP and WTA rankings. $V^{\text {ème }}$ Congrès de Physiologie de Pharmacologie et de Thérapeutique (P2T), Bordeaux, 23-25 March, pp 58

Hamilton WD (1966) The moulding of senescence by natural selection. J Theor Biol 12:12-45

Hayflick L (2007) Entropy explains aging, genetic determinism explains longevity, and undefined terminology explains misunderstanding both. PLoS Genet 3(12):e220

Howard RW (2005) Objective evidence of rising population ability: a detailed examination of longitudinal chess data. Pers Individ Differ 38:347-363

Hoye R, Smith A, Nicholson M, Stewart B, Westerbeek H (2009) Sport management: principles and applications, 2nd Edition. Oxford, Elsevier Butterworth-Heinemann

Husak JF (2006) Does survival depend on how fast you can run or how fast you do run. Funct Ecol 20:1080-1086

Irschick DJ, Meyers JJ, Husak JF, Le Galliard JF (2008) How does selection operate on whole-organism functional performance capacities? A review and synthesis. Evol Ecol Res 10:177-196

Kasemsap P, Crozat Y, Satakhun D (1997) Cotton leaf photosynthesis and age relationship is influenced by leaf position. Nat Sci 31:83-92 
Kitani K (2007) What really declines with age? The Hayflick Lecture for 2006 35th American aging association. Age (Dordr) 29:1-14

Kühnert B, Nieschlag E (2004) Reproductive functions of the ageing male. Hum Reprod Updat 10:327-339

Mandelbrot BB (1982) The fractal geometry of nature. Freeman, New York

Medawar PB (1952) An unsolved problem of biology. H.K. Lewis, London

Moore DH II (1975) A study of age group track and field records to relate age and running speed. Nature 253:264-265. doi: $10.1038 / 253264 \mathrm{a} 0$

Nevill AM, Whyte GP (2005) Are there limits to running world records? Med Sci Sports Exerc 37:1785-1788

Nevill AM, Whyte GP, Holder RL, Peyrebrune M (2007) Are there limits to swimming world records? Int J Sports Med 28:1012-1017

Njajou OT, Blackburn EH, Pawlikowska L, Mangino M, Damcott CM et al (2010) A common variant in the telomerase RNA component is associated with short telomere length. PLoS One 5(9):e13048

Reznick DN, Bryant MJ, Roff D, Ghalambor CK, Ghalambor DE (2004) Effect of extrinsic mortality on the evolution of senescence in guppies. Nature 431:1095-1099

Rittweger J, Prampero PE, Maffuli N, Narici MV (2009) Sprint and endurance power and ageing: an analysis of master atheltic word records. Proc R Soc B 276:683689

Roring RW, Charness N (2007) A multilevel model analysis of expertise in chess across the life span. Psychol Aging 22:291-299

Salthouse TA (2009) When does age-related cognitive decline begin? Neurobiol Aging 30:507-514

Schoenberg JB, Beck GJ, Bouhuys A (1978) Growth and decay of pulmonary function in healthy blacks and whites. Respir Physiol 33:367-393
Schulz R, Curnow C (1988) Peak performance and age among superathletes: track and field, swimming, baseball, tennis, and golf. J Gerontol 43:113-120

Stones MJ, Kozma A (1984) Longitudinal trends in track and field performances. Exp Aging Res 10:107-110

Tanaka H, Seals DR (2003) Invited review: dynamic exercise performance in masters athletes: Insight into effects of primary human aging on physiological 435 functional capacity. J Appl Physiol 95:2152-2162

Tanaka H, Seals DR (2008) Endurance exercise performance in masters athletes: age-associated changes and underlying physiological mechanisms. J Physiol 586:55-63

van Disseldorp JV, Faddy MJ, Themmen APN, de Jong FH, Peeters PHM, van der Schouw YT, Broekmans FJM (2008) Relationship of serum antimüllerian hormone concentration to age at menopause. J Clin Endocrinol Metab 93:2129-2134

Williams GC (1957) Pleiotropy, natural selection and the evolution of senescence. Evolution 11:398-411

Wright VJ, Perricelli BC (2008) Age-related rates of decline in performance among elite senior athletes. Am J Sports Med 36:443-450

Wullschleger SD, Oosterhuis DM (1990) Photosynthesis of individual field-grown cotton leaves during ontogeny. Photosyn Res 23:163-170

Young BW, Medic N, Weir PL, Starkes JL (2008a) Explaining performance in elite middle-aged runners: contributions from age, ongoing and past training factors. J Sport Exerc Psychol 30:737-754

Young BW, Weir PL, Starkes JL, Medic N (2008b) Does lifelong training temper age-related decline in sport performance? Interpreting differences between crosssectional and longitudinal data. Exp Aging Res 34:27-48

Young RD, Epstein L, Coles L (2009) Living and all-time world record holders over the age of 110 . Rejuvenation Res 12:231-232. doi:10.1089/rej.2009.0882 